\title{
HIPERGLICINEMIA NO CETÓSICA
}

Juan Augusto Perna Contreras, MD;* Clemencia Gutiérrez Sánchez, MD;** Héctor Alan Pérez Duarte, MD. **

\section{Resumen}

La hiperglicinemia no cetósica es una enfermedad autosómica recesiva, caracterizada por altas concentraciones de glicina en los líquidos corporales, sin encontrar ácidos orgánicos en sangre u orina, lo que la diferencia de la hiperglicinemia cetósica. La presentación clásica es la de un lactante menor con una enfermedad abrumadora; los sobrevivientes, a menudo tienen convulsiones intratables, asociadas a mioclonías y con poco o ningún desarrollo cerebral. el espectro comprende diferentes fenotipos clínicos: neonatal, infantil de inicio tardío y transitorio.

\section{Introducción}

La casuística colombiana, muestra un número considerable de familias afectadas por la hiperglicinemia no cetósica (Hgnnc), comparado con la frecuencia de otros desordenes del metabolismo de los aminoácidos. Las estadísticas muestran aproximadamente 12 nuevos casos en los últimos cinco años, siete de los cuales fueron confirmados con la relación de glicina en LCR/suero, que se obtiene al cuantificar el aminoácido en las dos muestras.

Un buen número de las familias con la enfermedad procede de la zona cafetera y la segunda frecuencia corresponde a Bogotá, de la que se desconoce en la mayoría de los casos la ciudad de nacimiento de los padres de los pacientes. El diagnóstico de la enfermedad sólo es validado, cuando se establece la relación de glicina en LCR/plasma, por cuantificación.

La mayoría de pacientes enferma durante los primeros días de vida y las manifestaciones clínicas (mala alimentación, incapacidad para succionar y letargia), pueden progresar en forma rápida hacia coma profundo, apnea y muerte. Esta afección suele ser mortal y las medidas terapéuticas actuales producen sólo una mejoría transitoria. ${ }^{1,2,3}$

* Pediatra UCIN Hospital de San José. **Residente III, Departamento de Pediatría Hospital de San José, Bogotá, D.C., Colombia Agradecimientos: doctor Alfredo Uribe. Jefe Centro de Investigaciones Bioquímicas, Universidad de los Andes

\section{Materiales y métodos Paciente 1}

Fecha de ingreso: 29 de diciembre de 2000; egreso 20 de febrero del 2001. Producto del segundo embarazo, en madre de 24 años. En el primer embarazo la recién nacida falleció a los 7 días de vida por causa no establecida. En esta ocasión la madre ingresa en expulsivo para la atención del parto, con edad gestacional de 30 semanas. Se realizó parto por cesárea con recién nacido de sexo masculino y Apgar de 2 al nacimiento, por lo que requiere reanimación, intubación orotraqueal y adrenalina.

Se inicia manejo en la unidad de cuidado intensivo neonatal: surfactante pulmonar en dos dosis, soporte inotrópico y terapia antibiótica, El estudio es positivo para asfixia perinatal con compromiso miocárdico y el cuadro clínico evoluciona de forma tórpida. Requiere transfusión con glóbulos rojos empa-quetados, albúmina e inmunoglobulina $\mathrm{G}$ enriquecida con IgM. Presenta un episodio convulsivo tónico-clónico generalizado, asociado con hipoxia y deterioro general por un proceso infeccioso. Ante el diagnóstico de meningitis, se cambia el esquema antibiótico, se inicia fenobarbital y a los 15 días de vida se toma ecografía transfontanelar que evidencia hemorragia intraventricular grado IV, asociada con hidrocefalia. Se efectúan punciones lumbares terapéuticas y al lograr la estabilización hemodinámica y respiratoria, se trasladó a la unidad de cuidado intermedio. 
Durante la evolución inicial del paciente se apreció tendencia a la hipocalcemia, picos de hipoglucemia, hiponatremia y acidemia metabólica. Cuando se traslada a cuidados intermedios aparece hipotonía, pobre succión y escasa ganancia de peso, por lo que se sospecha un error innato del metabolismo. Se solicita estudio en la Universidad de los Andes, el cual confirma Hgnnc. En la actualidad se administra alimentación con fórmula para prematuros por gavaje, fenobarbital para el control del cuadro neurológico, además de terapia física y del lenguaje. Se explica a la madre la enfermedad del paciente y la necesidad de consejería genética. El día 20 de enero se decide dar salida con indicaciones y manejo por plan canguro.

\section{Paciente 2}

Producto de segundo embarazo en madre de 24 años, que cursó con leucorrea durante el séptimo mes de gestación. El parto fue pretérmino, de 34 semanas con ruptura prematura de membranas, peso al nacer de 2.500 gramos y talla de $45 \mathrm{~cm}$ (13 de marzo de 2000), Apgar bajo al nacimiento, parto atendido en el hospital de San Ignacio de Bogotá D.C., donde permaneció durante 17 días con diagnóstico de pretérmino de peso adecuado, hipoglucemia de etiología no clara, ictericia y síndrome convulsivo. Salió con fórmula de fenobarbital.

Ingresa por primera vez al hospital de San José el 25 de abril de 2.000 , a la edad de 45 días, por disminución progresiva del apetito asociada con hipotonía generalizada. Al examen físico de ingreso pesa 1.950 gramos y mide $45 \mathrm{~cm}$. Presenta hipotonía, hiporreflexia y escasa reacción a los estímulos, además de trofismo disminuido y hernia inguinal izquierda. A su ingreso hay hipoglucemia, por lo cual se decide hospitalizar con los diagnósticos de hipoglucemia sintomática y desnutrición crónica. Se solicita estudio de errores innatos del metabolismo a la Universidad de los Andes. La hipoglucemia cede con tratamiento convencional y se inicia la vía oral, con escasa ganancia de peso. La resonancia magnética cerebral informa cambios por hipoxia perinatal; se inicia terapia física con leve mejoría del cuadro neurológico. Se decide dar salida cuando hay una ganancia constante de peso y se realiza entrenamiento materno para el manejo del paciente, quedando pendiente el informe del estudio de errores innatos del metabolismo.

El niño asiste a control por consulta externa con resultado del estudio metabólico, el cual informa Hgnnc. Se explica a la madre el comportamiento de la enfermedad, el pronóstico del paciente y se envía a consejería genética.

Reingresa al hospital el 7 de junio de 2.000 en estatus convulsivo, requiere infusión de benzodiazepinas, pero evoluciona en forma tórpida con hipoglucemia, acidosis metabólica y fallece el 9 de junio de 2.000.

\section{Discusión}

La Hgnnc es una enfermedad autosómica recesiva con un amplio espectro de fenotipos clínicos: neonatal, infantil de inicio tardío y transitoria. Se debe a una alteración del sistema de clivaje de la glicina, que la convierte en $\mathrm{CO}_{2}, \mathrm{NH} 3$ y tetrahidrofolato (Figura 1).

La glicina es un aminoácido no esencial, simple, pero tiene un patrón complejo de metabolismo, que puede ser sintetizado por el ser humano. Está presente en altas concentraciones en el colágeno y la gelatina y abunda en la mayoría de las proteínas animales. La ingesta diaria para un adulto promedio en Estados Unidos es de 3 a $5 \mathrm{~g}$.

La glicina recibió inicialmente un nombre que recuerda al azúcar, debido a su sabor dulce. Tam-

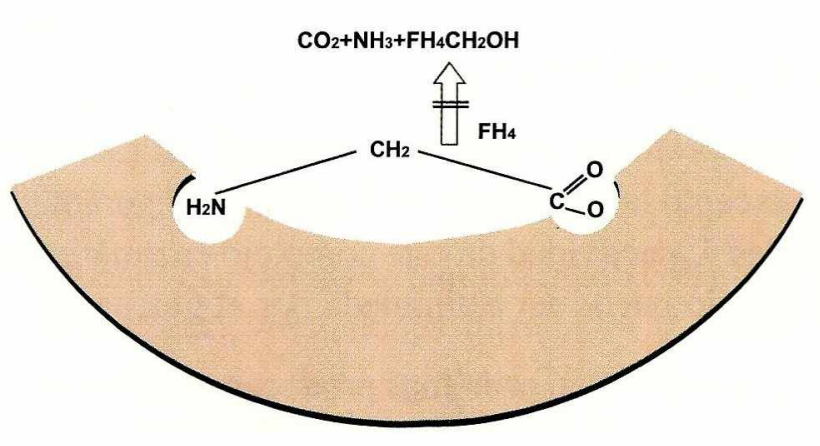

Figura 1. Sitio de defecto en la reacción del clivaje de la glicina 
bién es un aminoácido glucogénico, pues si se alimenta un animal en ayuno con grandes cantidades de glicina se deposita glucógeno en el hígado. La glicina tiene un papel importante en la síntesis de purinas, glutatión y del delta aminovulinato, que a su vez es el precursor de la porfirina y del hem.

Este aminoácido se utiliza en varias reacciones de conjugación que son útiles en el proceso de detoxificación; se conjuga con ácido benzoico para formar hipurato y con salicilatos para formar ácido salicilúrico, los cuales son excretados por la orina. La colina se conjuga con la glicina para formar el ácido biliar glicocolato, que se excreta en el intestino.

En el sistema nervioso central es uno de los tres neurotransmisores más abundantes, junto con el glutamato y el GABA. En la médula espinal tiene un papel inhibidor y en la corteza cerebral y otras regiones del cerebro anterior cumple una función excitadora.

La principal vía en el catabolismo es el sistema de clivaje de la glicina, que es un complejo de 4 péptidos ubicado en la membrana mitocondrial interna del hígado, riñón, cerebro y placenta. ${ }^{1}$

En primer lugar se libera el grupo carboxilo de la glicina, por acción de las proteínas $\mathrm{P}$ y $\mathrm{H}$, con producción de $\mathrm{CO}_{2}$ y participación de la piridoxina como catalizador. El siguiente paso catalizado por la proteína $\mathrm{T}$, requiere el concurso del tetrahidrofolato y consiste en la liberación del grupo amino de la glicina como $\mathrm{NH}_{3}$ y transfiere al carbono alfa de la glicina al tetrahidrofolato, formando 5, 10 metilentetrahidrofolato. Por último la proteína $\mathrm{L}$, que es una lipoamido deshidrogenasa, y el NAD reoxidan la forma ditiol de la proteína $\mathrm{H}$ a la forma disulfito (Figura 2).

Las proteínas del complejo se disocian fácilmente, excepto las proteínas P y L que están ligeramente unidas. La actividad de este complejo enzimático en el hígado puede ser estimulada por el glucagón.

Dietas ricas en proteínas producen aumento en la secreción de éste y dan lugar a una relación glucagón: insulina, cuyo resultado es un aumento de la activi-

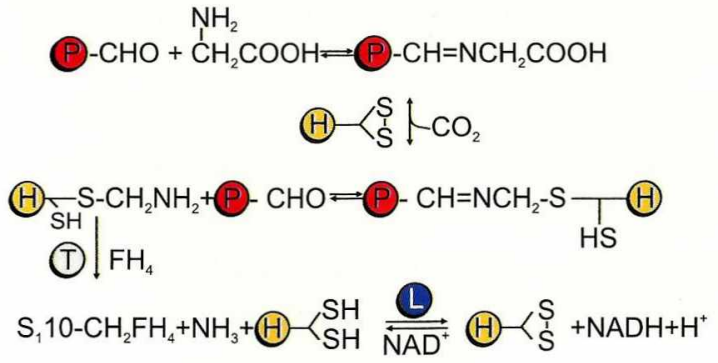

Figura 2. Sistema de clivaje de la glicina

dad del citado sistema, mediado por un aumento del AMPc y del calcio libre; algo similar ocurre con el estímulo de receptores alfa-adrenérgicos.

Otra vía de degradación de la glicina menos importante que la anterior, es la glicina hidroximetilasa, enzima ubicada a nivel citoplasmático. Por medio de esta vía se convierte la glicina en serina, en presencia de $\mathrm{CO}_{2}$ y $\mathrm{NH}_{3}$. Esta reacción es reversible, y en condiciones normales el flujo neto va en dirección de la conversión de serina en glicina. En estado de ayuno esta reacción constituye una fuente importante de serina y piruvato. Otras vías catabólicas menores son la conversión de glicina en glioxilato por una glicina oxidasa y la condensación de la glicina con acetil coA para formar aminoacetona.

Alrededor de $70 \%$ de los genes de Hgnnc de origen finlandés tienen una mutación en la proteína PP, que ocasiona una sustitución de guanina por timina en el nucleótido 1691, codificando una proteína $\mathrm{P}$ sin actividad, que causa una alteración en el aminoácido 754. También se ha descrito en un paciente japonés una deleción del aminoácido 7556 de la proteína $\mathrm{P}$ y no se han descrito defectos moleculares específicos de las proteínas $\mathrm{H}$ o T. ${ }^{4}$

Esta entidad se trasmite en forma autosómica recesiva, el gen de la glicina decarboxilasa se encuentra ubicado en el brazo corto del cromosoma 9, comprende aproximadamente 135 kilobases que se expresa en el hígado, cerebro y placenta. El estado de portador puede ser difícil de descubrir desde el punto vista bioquímico. ${ }^{5}$

Están descritos tres fenotipos clínicos asociados a la Hgnnc. La forma neonatal es la más impresio- 
nante y frecuente; los pacientes suelen ser productos de embarazos y partos sin complicaciones, pueden permanecer asintomáticos durante el primer día de vida, pero luego presentan hipotonía, letargia, rechazo a la alimentación, movimientos oculares anormales y oftalmoplejía. Muchos de ellos cursan con crisis convulsivas mioclónicas o generalizadas, casi siempre de difícil control. En la medida en que progresa la encefalopatía y el compromiso del estado de conciencia hasta llegar al coma, los lactantes presentan movimientos mioclónicos segmentarios, episodios de apnea e hipo.

La mayoría de estos recién nacidos requiere asistencia ventilatoria en las primeras semanas de vida y cerca del $30 \%$ mueren en el período neonatal. Aquellos que sobreviven usualmente reasumen la respiración espontánea alrededor de la tercera semana de vida y la supervivencia oscila entre algunos meses y 22 años. Muchos pueden volver a succionar, pero la mayoría requiere alimentación por gavaje. Aquellos sin tratamiento presentan convulsiones refractarias hacia los doce meses; el patrón de convulsiones comienza con movimientos mioclónicos y evoluciona a espasmos infantiles, convulsiones motoras parciales o tónicas.

El retraso sicomotor es severo con bajo comportamiento de adaptación; a menudo la hipotonía inicial progresa a cuadraplejia espástica.

En las primeras dos semanas de vida el patrón electroencefalográfico característico es de explosiónsupresión, después la actividad eléctrica evoluciona a ondas lentas de alto voltaje y hacia el tercer mes aparece hipsarritmia; en general, no se correlaciona con el estado de actividad clínica del paciente y después del año los trazados revelan lenificación, así como frecuentes descargas de puntas multifocales independientes. Los potenciales evocados auditivos sugieren una lentificación de la conducción a través de la vía auditiva. Los potenciales visuales, reportados con menor frecuencia, pueden ser anormales.

La toxicididad por glicina puede empezar en el útero. De hecho, se han descrito anormalidades del cuerpo calloso, entre las cuales se encuentra la age- nesia y la degeneración espongiforme de la sustancia blanca.

\section{Hiperglicinemia no cetósica atípica}

Se observa con manifestaciones clínicas tardías o presentaciones incompletas de la enfermedad.

\section{Hiperglicinemia transitoria}

Es indistinguible de la Hgnnc neonatal y cursa con niveles elevados de glicina en plasma y líquido cefalorraquídeo(LCR) que vuelven a cifras normales a la segunda y octava semanas de vida. Al parecer se relaciona con una inmadurez en el sistema de clivaje de la glicina en el hígado y el cerebro. No hay evidencia de etiología genética. ${ }^{1,2,3}$

Estos enfermos presentan valores plasmáticos y urinarios de glicina entre dos y ocho veces el normal; en el LCR se pueden encontrar concentraciones entre 15 y 30 veces por encima de lo normal y existe cierto grado de correlación entre estas cifras y el fenotipo clínico. La glicina en el LCR varía entre 1 y $1,7 \mathrm{mg} / \mathrm{dL}$ en pacientes con Hgnnc cuyas cifras séricas normales están por debajo de $0,1 \mathrm{mg} / \mathrm{dL}$ La relación entre las cifras de LCR y de plasma es más alta en estos pacientes: $(0,17+/-0,09)$ mientras que la relación en individuos normales es de 0,02. Es posible que haya algún grado de asociación con la severidad clínica.

El paciente descrito por Gerritsen excretaba entre uno y tres gramos de glicina al día, en tanto un adulto normal excreta un gramo al día ó 0,1 a 0,2 $\mathrm{mg} / \mathrm{mg}$ de creatinina. Es fácil pasar por alto un enfermo con hiperglicinemia cuando se realiza cromatografía en papel o electroforesis. En general para establecer el diagnóstico es mejor la medición de la glicina en la sangre que en la orina.

Muchas estrategias se han intentado con el fin de disminuir las convulsiones intratables y lentificar la progresión del daño cerebral. No obstante hasta la fecha ninguna ha demostrado una efectividad uniforme. De acuerdo con ellas se divide el tratamien- 
to así: reducción de la glicina mediante dieta libre de ella y de serina, pero no ha tenido efecto sobre la frecuencia de las convulsiones ${ }^{7} \mathrm{ni}$ el progreso del desarrollo sicomotor.

La alternativa es la administración de benzoato que conjuga la glicina para formar hipurato y se excreta por la orina. Las dosis oscilan entre $150 \mathrm{y}$ $750 \mathrm{mg} / \mathrm{kg} /$ día. Si bien disminuyen las concentraciones plasmáticas de glicina a lo normal y la de LCR baja, solo produce una reducción en la frecuencia de las convulsiones, pero en ningún caso ha mejorado el desarrollo sicomotor de estos ninos. $^{2}$

Donantes de carbonos únicos: algunos usan la metionina en conjunto con una dieta baja en glicina y serina, pero sin efectos clínicos. Otros utilizan leucoborín, colato y/o colina con dieta o medidas farmacológicas (benzoato); sin cambios en la frecuencia de las crisis convulsivas o en el desarrollo psicomotor.

El bloqueo del receptor es una estrategia razonable, al considerar que el mecanismo de las convulsiones está mediado por $\mathrm{N}$-metil D-aspartato; se ha intentado el uso de la estricnina, con una respuesta clínica variable, además de que podría empeorar las convulsiones y el daño cerebral.

El diazepam, junto con el benzoato y el ácido fólico fueron utilizados con éxito para el tratamiento de las convulsiones intratables en dos niñas con esta entidad. También se ha empleado la ketamina sumada a benzoato, así como el dextrometorfano en dosis entre 5 y $35 \mathrm{mg} / \mathrm{kg} /$ día. Además, parece que el benzoato podría, en algunos casos, retardar la progresión de la enfermedad. ${ }^{1}$
Queda por determinar la utilidad de nuevos anticonvulsivantes que actúan sobre el receptor para Nmetil D-aspartato, como es el caso de felbamato.

\section{Conclusiones.}

Se presentan dos pacientes prematuros, con infección neonatal y en quienes se sospecharon errores innatos del metabolismo por hipoglucemia, convulsiones, pobre ganancia de peso, hipotonía y letargia. Consideramos que la sospecha clínica es la piedra angular para el diagnóstico precoz de los errores innatos del metabolismo, pues son enfermedades monogénicas, secundarias al defecto de una proteína, que causa algún bloqueo en la vía metabólica, con repercusiones clínicas en el organismo. Creemos que el estudio metabólico del prematuro debe incluir, en lo posible, la cromatografía de aminoácidos.

\section{Referencias}

1. Stamboy JB, Wyngarden JB. Errores innatos del Metabolismo, $5^{\text {a }}$ ed. Mac Graw Hill, 1983.

2. Behrman R, Kliegman R, Arbin A. Tratado de Pediatria, $15^{\mathrm{a}}$ ed. Mac Graw Hill Panamericana, 1997. p411-526.

3. Loredo A. Medicina Interna Pediátrica, $3^{\mathbf{a}}$ ed. México Mac Graw Hill, 1996.

4. Hayasaka K et al. Nonketotic Hyperglycinemia: Analysis of glycine cleavage system in typical and atypical cases. J.Pediatrics 1987; 110: 873.

5. Kure, Shigeo et al. Identification of a Common Mutation in Finnish patients with Nonketotic Hyperglycinemia. J. Clin, Invest 1992; 90: 160-4.

6. Scriver C et al: Plasma-CSF Glycine Ratio in normal and Nonketotic Hyperglycinemic subjects. N.England J.Med 1975; 293: 778.

7. Wolff J,et al. The Effectiveness of Benzoate in the Management of Seizures in Nonketotic Hyperglycinemia. A.J.D.C. 1986; 140: 596-602.

8. Hamosh A, et al. Dextrometorphan and high-12 benzoate the therapyc for Nonketotic Hyperglycenemia in an infant. J.Pediatrics; 1992; 121: 131-5. 